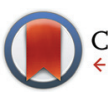

CrossMark

Cite this: Food Funct., 2016, 7, 2937

\title{
Drinking pattern of wine and effects on human health: why should we drink moderately and with meals?
}

\author{
Mladen Boban, ${ }^{* a}$ Creina Stockley, ${ }^{b}$ Pierre-Louis Teissedre, ${ }^{c}$ Patrizia Restani, ${ }^{d}$ \\ Ursula Fradera, ${ }^{e}$ Claudia Stein-Hammer ${ }^{e}$ and Jean-Claude Ruff
}

\begin{abstract}
Conclusions of epidemiological studies examining the effects of alcoholic beverages on human health may be unclear and limited if they do not take into account drinking pattern parameters such as beverage type, regular moderate versus binge drinking and drinking with or without meals. This review considers different aspects of drinking patterns and effects on human health with special attention to wine. We particularly discuss the potential underlying mechanisms for epidemiological evidence that the beneficial effects of wine are more evident if consumed with food. In this context, we address the effects of food on blood alcohol concentration and acetaldehyde production in the gastrointestinal tract, the role of wine components and uric acid in counteracting the detrimental effects of postprandial oxidative stress, as well as wine's antimicrobial properties and its potential to act as a digestive aid. In addition to its biological correlates, drinking patterns with regard to different socio-cultural circumstances in different populations are also considered. In order to avoid confusion and misconceptions in the general population because of the hormetic associations of wine with human health, it is important that all medical and scientific information concerning the effect of wine consumption on human health are evidence-based and communicated in a competent, credible and unbiased manner. In conclusion, we propose several practical recommendations concerning wine consumption and consumer information to minimize the risks of alcohol-related harm and to encourage individual responsibility and a healthy lifestyle.
\end{abstract}

Received 19th February 2016 Accepted 13th June 2016

DOI: $10.1039 / \mathrm{c} 6 f \circ 00218 \mathrm{~h}$

www.rsc.org/foodfunction

\section{Introduction}

Even though alcohol consumption has been decreasing in many regions of the world over the last 20 years, alcoholrelated problems have increased in different societies. Harmful and hazardous consumption of alcoholic beverages, especially among young people, has become a major social, economic and health problem in many countries throughout

\footnotetext{
${ }^{a}$ Department of Pharmacology, University of Split School of Medicine, Soltanska 2, 21000 Split, Croatia. E-mail: mladen.boban@mefst.hr; Fax: +38521465 073; Tel: +38521557904

${ }^{b}$ The Australian Wine Research Institute, PO Box 197, Glen Osmond 5061, SA, Australia

${ }^{c}$ Univ. Bordeaux, ISVV, EA 4577, QEnologie, 210 chemin de Leysotte and INRA, ISVV, USC1366 QEnologie, F-33140 Villenave d'Ornon, France

${ }^{d}$ Dept. Pharmacological and Biomolecular Sciences, Università degli Studi di Milano, via Balzaretti 9, 20133 Milano, Italy

${ }^{e}$ Deutsche Weinakademie, Gutenbergplatz 3-5, 55116 Mainz, Germany

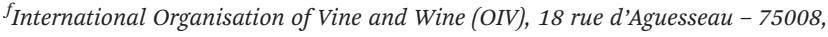
Paris, France
}

the world. Alcohol is a significant contributor to the global burden of disease and it is the third most important risk factor globally, and the most important in middle-income countries. ${ }^{1,2}$ It is estimated that harmful alcohol use is the third biggest cause of early death and illness in the European Union. ${ }^{3}$ Also, there is a clear relationship between heavier alcohol intake and different types of cancers, particularly those of the digestive tract, liver and breast. ${ }^{4-7}$

There is evidence, however, that light-to-moderate consumption of alcoholic beverages, especially wine, is associated with a lower risk of cardiovascular diseases, and all-cause mortality. ${ }^{8-15}$ Moderate wine consumption is also related to a lower risk of diabetes mellitus, ${ }^{16,17}$ cardiometabolic complications in diabetic patients, ${ }^{18,19}$ and declining cognitive function. ${ }^{20,21}$

The associations of wine consumption with human health are complex: they can cause confusion in the general population and lead to misconceptions about the effect of wine consumption on human health. Hence, evidence-based knowledge and education of the general public, health and 
social policy professionals as well as the relevant media, are prerequisites for the successful implementation of national alcohol policies.

\section{Aspects of drinking patterns and human health}

It has been repeatedly emphasized that information on average alcohol consumption-irrespective of beverage type-is not sufficient when describing alcohol-related morbidity and mortality, and that epidemiological studies examining the effects of alcohol on human health should include measures of drinking patterns. ${ }^{22,23}$

Unfortunately, many epidemiological studies examining the effects of alcohol are incomplete or lack information on drinking patterns with regard to beverage type, regular moderate versus binge drinking and drinking with or without meals. Consequently, the conclusions of such studies may be unclear and limited.

This is reflected in a three-fold to six-fold higher risk of a major coronary event when consuming up to $200 \mathrm{~g}$ ethanol within one or two days rather than distributed over a week. ${ }^{24}$ It has also been shown that repeated 'binge drinking' is associated with higher 'all-cause' mortality than light to moderate drinking and abstinence..$^{23,25-27}$ Conversely, a recent study examining the relationship between an overall alcohol-drinking pattern and all-cause mortality indicated that high adherence to a traditional Mediterranean alcohol-drinking pattern could reduce mortality beyond the reduction observed when only moderate alcohol intake was taken into account. ${ }^{28}$ By simultaneous assessment of seven measures of drinking patterns (moderate alcohol intake, alcohol intake spread out over the week, low spirit consumption, wine preference, red wine consumption, wine consumed during meals and avoidance of binge drinking) the authors also observed a lower rate of mortality among wine drinkers compared with non-wine drinkers.

Besides the factors relating to the drinking patterns that are subject to the consumer's self-control, the J-shaped relationship between the intake of alcoholic beverages and mortality from cardiovascular diseases may also be influenced and modified by other factors, ${ }^{11}$ such as age, ${ }^{29,30}$ gender $^{31}$ and genetic variations. $^{32}$

Some epidemiological evidence suggests that the cardioprotective effects of wine are more evident in individuals who consume wine with food. ${ }^{33-35}$

A marked suppression of postprandial hydroperoxides was found when food was consumed with wine, suggesting that these hydroperoxides can be formed during the digestive process and then act at the systemic level. ${ }^{36}$ Supportive of this are findings of some interventional studies showing that drinking moderate amounts of red wine mitigates oxidative stress and vascular endothelial damage induced by a high-fat meal $;^{37,38}$ and that it may reduce the susceptibility of human plasma and LDL to lipid peroxidation ${ }^{39}$ as well as protect diabetic patients from meal-induced oxidative stress and thrombosis activation. ${ }^{40}$ It should be noted, however, that protective effects of wine against oxidative damage are influenced by the type of food and may be less pronounced in individuals consuming a well-balanced diet. ${ }^{41,42}$

Wine contains ethanol, phenolic compounds and many other naturally-occurring bioactive compounds. Cardioprotective effects have been particularly attributed to ethanol ${ }^{43}$ and to phenolic components. ${ }^{44}$ These components act in a complementary way on cholesterol, blood clotting and blood flow, and on vascular endothelial function. In addition to the winederived phenolic compounds themselves, their metabolites formed in the small intestine and hepatic cells as well as low molecular weight catabolic products of the colonic microbiota, may also play an important role in the different biological effects of wine. $^{45,46}$

Studies have shown that after ingesting a moderate amount of wine, the antioxidant activity in the serum increases. ${ }^{47,48}$ Initially, this effect was primarily attributed to the highly concentrated phenolic compounds in wine, especially in red wine. ${ }^{49,50}$ Later, it was shown that the acute increase in plasma antioxidant capacity following wine consumption is mainly mediated by the moderately increased level of plasma uric acid. ${ }^{51,52}$ Thus, the antioxidant activity is influenced by two separate mechanisms, wine-derived phenolic compounds and plasma urate. ${ }^{53}$

If the wine is consumed with meals, onset of the plasma uric acid elevation coincides with the period of postprandial oxidative stress, which may contribute to the wine's protective effects. Consistent with this is a critical review of studies relating to moderate wine consumption with oxidative damage in humans, which concluded that the cardioprotective effects of moderate wine consumption are best demonstrated during the meal-related period of postprandial oxidative stress. $^{54}$ These parallel mechanisms provide support for the positive effects of wine in spite of the low concentrations of phenolic compounds measured in human blood after wine consumption. $^{55}$

Furthermore, the unabsorbed phenolic compounds that remain in the gastrointestinal system following wine consumption may also contribute to the anti-oxidant effects of wine. There they can scavenge free radicals locally, preventing lipid peroxidation as well as the absorption of cytotoxic lipid peroxidation products. ${ }^{56-58}$

Another important argument in favor of consuming wine with food is the lowering effect on blood alcohol concentration (BAC). It was demonstrated that food in the stomach before drinking alcoholic beverages not only lowers the peak BAC, but also boosts the rate of ethanol metabolism and elimination. ${ }^{59,60}$

If the BAC exceeds $0.8-1 \%$ o (and even less in women), the break down capacity of the liver's alcohol dehydrogenase enzyme system becomes saturated, and the liver has to switch to the microsomal ethanol oxidizing system (MEOS) to metabolize the alcohol. This MEOS pathway, however, generates oxidative free radicals that can damage the liver tissue in the long-term. ${ }^{61}$ 
In addition to the BAC lowering effect, food may also act as a mechanical 'wash-out' of alcohol from the oral mucosa, thereby decreasing the risk of ethanol-associated carcinogenesis in the oral cavity and upper gastrointestinal tract. Namely, oral microbiota can effectively metabolize alcohol into acetaldehyde, which is carcinogenic and is thought to play a major role in the tumor-promoting action of alcohol. ${ }^{62,63}$ Hence, drinking with a meal could provide additional positive effects by decreasing alcohol availability to oral microbiota.

A further important biological property of wine is its potent antimicrobial activity including human foodborne, medical and oral pathogens. ${ }^{64,65}$ Numerous wine-based marinades have been shown to be effective against the detrimental effects of foodborne pathogens and background flora on meat products. ${ }^{64,66,67}$ Thus, in addition to the improvement of microbial food safety, wine consumed with a meal may also be protective against alimentary infections. ${ }^{68,69}$

In addition to the described short-term effects of wine, there are long-term effects which are mediated by its constituents, but elaboration of those effects and of the associated underlying molecular mechanisms exceeds the scope of this article.

\section{Drinking patterns, socio-cultural circumstances and educational aspects}

Alcoholic beverages, including wine are consumed by almost half the world's population, although there is considerable variation between and within countries, since its consumption is an aspect of social and cultural habits. While wine consumption in different regions of the world has fallen considerably over the past 20 years, among young people there has been a gradual global increase in the misuse of alcoholic beverages in general, particularly in the form of 'binge drinking, ${ }^{70,71}$ There are, however, considerable national variations in 'binge drinking' behaviors. The European Comparative Alcohol Study (ECAS) looked at trends in drinking patterns among adults and reported lower rates of binge drinking in Southern European traditional wine drinking countries than in Northern and Central Europe where beer and spirits are the preferred beverages. ${ }^{72}$ A similar drinking pattern was observed among young people. In countries where the students drink often, for example in Greece, the total amount of alcohol consumed per drinking occasion is usually low. The opposite and hence a more risky drinking pattern was reported from countries with low consumption frequencies such as the Nordic countries. ${ }^{73}$ Thus, it seems that the cultural differences regarding drinking patterns are reflected in young people's behavior.

In some societies, misuse of alcoholic beverages is often associated with violent or anti-social behavior, while in others, drinking behavior may be more harmonious. These differences are partly related to inconsistent cultural beliefs about the consumption of alcoholic beverages, expectations regarding the effects of alcohol, and social norms regarding drunkenness and intoxication. ${ }^{74-76}$

It is widely recognized that a spectrum of measures including education and the provision of medical and scientific information is essential to encourage individual responsibility and at the same time to discourage behaviors that lead to abuse and excess. ${ }^{77-81}$ For successful implementation of public health campaigns about risky drinking behaviors, application of the "audience segmentation" principle could be a useful approach. For example, light and moderate drinkers who rarely engage in binge drinking may be more likely than heavy drinkers to abide with a campaign's messages and to improve their drinking habits and lifestyle. Heavy drinkers, on the other hand, may require more individualized and intensive interventions to change their behavior. ${ }^{82}$

All medical and scientific information concerning the effects of alcoholic beverages on health must be evidencebased and presented in a competent, credible and unbiased manner.

In the case of children, adolescents and young adults, parents and school staff should be particularly supported to effectively educate about responsible consumption patterns and practices ${ }^{83-85}$ since parents as well as peer groups can significantly influence behavior. ${ }^{86-88}$ The educational programs for young people must take into account the social, legal, economic and cultural aspects suitable for each country.

Unfortunately, most educational programs focus on the negative consequences without proposing recommendations for a healthy lifestyle and moderate consumption of alcoholic beverages with appropriate self-control, to minimize the risks of harm to health and society. ${ }^{89-91}$ This is the case because individual risk factors cannot be assessed. However, based on the available scientific evidence, adults who consume wine with meals regularly and moderately, in most circumstances experience more health benefits than risks. ${ }^{92,93}$

In conclusion, the following recommendations regarding wine consumption and consumer information are proposed:

\section{Information and education on responsible wine consumption}

It is important to provide individuals with relevant, credible, balanced and accurate information so that they can make informed decisions. It is also important to provide education in life skills in the broadest sense to promote sensible drinking patterns and cultural change in the approach to wine, in order to reduce alcohol-related harm.

\section{Moderate wine consumption}

The optimal amount of wine for gaining maximal benefits and for minimizing alcohol-related health risks cannot be precisely prescribed, because of large inter-individual differences. Instead, it is more appropriate to talk about the range of wine intake that reflects the term "moderate". Based on the results of numerous epidemiological and interventional studies, it is suggested that a daily intake of 200 to $300 \mathrm{~mL}$ of an average wine for men (approximately 20 to $30 \mathrm{~g}$ ethanol), and 100 to 
$200 \mathrm{~mL}$ for women (approximately 10 to $20 \mathrm{~g}$ ethanol), corresponds with the targeted range of light to moderate wine consumption associated with a lower risk of cardiovascular diseases and all-cause mortality.

\section{Drinking patterns}

Different drinking patterns and their consequences need to be understood in context, so that effective solutions can be determined, developed and implemented. Drinking patterns in terms of frequency and the amount of wine consumed as well as drinking with or without a meal are important influencing factors for the biological effects of wine. Risky and harmful drinking patterns including the regular consumption of high amounts of wine, as well as consuming large amounts on a single occasion (binge drinking), should be discouraged. It is thus recommended that individuals drink wine as an accompaniment to food, and alternate it with a non-alcoholic beverage such as water.

\section{Harmful effects of abusive wine consumption}

Excessive and hazardous consumption of alcoholic beverages including wine has both short-term and long-term harmful effects on health. The short-term effects are primarily an increased risk of accidents, aggressive and violent behaviors and suicides. The longer-term effects are risk of diseases such as hemorrhagic stroke, liver cirrhosis, pancreatitis and certain cancers. Indeed, heavy consumption of alcoholic beverages can be a direct or an additional detrimental risk factor in many diseases, combined with other individual risk factors such as diet, genetic predisposition, obesity, smoking and physical inactivity.

\section{Situations when wine consumption should be avoided}

Pregnancy and breastfeeding. Maternal consumption of alcoholic beverages including wine can harm the developing fetus or a breastfed baby. Although a threshold for harm has not yet been determined for women who are pregnant, planning a pregnancy or breastfeeding, taking into account the "precautionary principle", not consuming any alcoholic beverages is the safest option.

BAC and driving. The conditions for increasing the blood alcohol concentration (BAC) vary between individuals and take into account criteria such as body size and weight, gender, concurrent drug and food consumption, and the general health of an individual. Alcoholic beverages, including wine, should be avoided by individuals who plan to operate machinery, or take part in other activities that require attention and coordination skills as well as by individuals who plan to drive, to keep the blood alcohol concentration low, and below the legal limits of driving set by different countries.

Adolescents and young adults. For adolescents, the safest option is not to consume any alcoholic beverages. Drinking at an early age enhances the likelihood of developing alcoholrelated mental health disorders and dependence, while abusive alcohol consumption impedes brain development.
Similarly, young adults should limit their alcohol consumption and never drink to intoxication. In addition, increased risk taking behaviors are associated with these age groups, which may be exacerbated by alcohol consumption.

Individuals with an increased risk of harm. Specific individuals may be at increased risk of harm, if they drink alcoholic beverages. These include individuals with:

- a family history of alcohol abuse and dependence;

- mental health problems;

- specific diseases or physical conditions that can deteriorate or be affected by alcohol, especially the liver and pancreas; and

- individuals who use certain over-the-counter or prescription medications, or recreational drugs.

Individuals who should seek professional advice about their drinking habits. Specific individuals may need to seek professional advice about their drinking habits, because of the possible adverse interactions and associated harmful effects. These include:

- individuals with alcohol-related, mental health or physical conditions that can be worsened or affected by alcohol; and

- individuals who are concerned about their drinking habits.

\section{Acknowledgements}

The authors are government delegates and/or experts to the International Organisation of Vine and Wine's (OIV) Commission IV Safety and Health. Although this work was initiated under the auspices of the OIV and its Consumption, Nutrition and Health expert group, the statements herein are the sole responsibility of the undersigned authors.

\section{References}

1 W. H. O. (WHO), Global strategy to reduce harmful use of alcohol., Geneva, Switzerland, 2010.

2 W. H. O. (WHO), Global status report on alcohol and health, Geneva, Switzerland, 2014.

$3 \mathrm{EU}$, Alcohol-related harm in Europe - Key data, MEMO/06/397, Brussels, Belgium, 2006.

4 F. Turati, C. Galeone, M. Rota, C. Pelucchi, E. Negri, V. Bagnardi, G. Corrao, P. Boffetta and C. La Vecchia, Ann. Oncol., 2014, 25, 1526-1535.

5 Y. Cao, W. C. Willett, E. B. Rimm, M. J. Stampfer and E. L. Giovannucci, Br. Med. J., 2015, 351, h4238.

6 A. L. Klatsky, Y. Li, H. Nicole Tran, D. Baer, N. Udaltsova, M. A. Armstrong and G. D. Friedman, Perm. J., 2015, 19, 28-34.

7 V. Bagnardi, M. Rota, E. Botteri, I. Tramacere, F. Islami, V. Fedirko, L. Scotti, M. Jenab, F. Turati, E. Pasquali, C. Pelucchi, C. Galeone, R. Bellocco, E. Negri, G. Corrao, P. Boffetta and C. La Vecchia, Br. J. Cancer, 2015, 112, 580593. 
8 M. Bonaccio, A. Di Castelnuovo, S. Costanzo, M. Persichillo, A. De Curtis, M. B. Donati, G. de Gaetano and L. Iacoviello, Eur. J. Cardiol., 2016, 23, 400-407.

9 S. Costanzo, A. Di Castelnuovo, M. B. Donati, L. Iacoviello and G. de Gaetano, Eur. J. Epidemiol., 2011, 26, 833850.

10 A. Di Castelnuovo, S. Rotondo, L. Iacoviello, M. B. Donati and G. De Gaetano, Circulation, 2002, 105, 2836-2844.

11 M. Gronbaek, Curr. Opin. Lipidol., 2006, 17, 17-21.

12 M. Gronbaek, A. Deis, T. I. A. Sorensen, U. Becker, P. Schnohr and G. Jensen, Br. Med. J., 1995, 310, 11651169.

13 K. J. Mukamal, A. Ascherio, M. A. Mittleman, K. M. Conigrave, C. A. Camargo Jr., I. Kawachi, M. J. Stampfer, W. C. Willett and E. B. Rimm, Ann. Intern. Med., 2005, 142, 11-19.

14 A. S. St Leger, A. L. Cochrane and F. Moore, Lancet, 1979, 1, 1294.

15 S. G. Wannamethee and A. G. Shaper, Am. J. Public Health, 1999, 89, 685-690.

16 V. G. Athyros, E. N. Liberopoulos, D. P. Mikhailidis, A. A. Papageorgiou, E. S. Ganotakis, K. Tziomalos, A. I. Kakafika, A. Karagiannis, S. Lambropoulos and M. Elisaf, Angiology, 2008, 58, 689-697.

17 A. M. Hodge, D. R. English, K. O'Dea and G. G. Giles, Diabetic Med., 2006, 23, 690-697.

18 Y. Gepner, R. Golan, I. Harman-Boehm, Y. Henkin, D. Schwarzfuchs, I. Shelef, R. Durst, J. Kovsan, A. Bolotin, E. Leitersdorf, S. Shpitzen, S. Balag, E. Shemesh, S. Witkow, O. Tangi-Rosental, Y. Chassidim, I. F. Liberty, B. Sarusi, S. Ben-Avraham, A. Helander, U. Ceglarek, M. Stumvoll, M. Bluher, J. Thiery, A. Rudich, M. J. Stampfer and I. Shai, Ann. Intern. Med., 2015, 163, 569-579.

19 J. I. Blomster, S. Zoungas, J. Chalmers, Q. Li, C. K. Chow, M. Woodward, G. Mancia, N. Poulter, B. Williams, S. Harrap, B. Neal, A. Patel and G. S. Hillis, Diabetes Care, 2014, 37, 1353-1359.

20 K. A. Arntzen, H. Schirmer, T. Wilsgaard and E. B. Mathiesen, Acta Neurol. Scand., Suppl., 2010, 2329.

21 J. M. Orgogozo, J. F. Dartigues, S. Lafont, L. Letenneur, D. Commenges, R. Salamon, S. Renaud and M. B. Breteler, Rev. Neurol., 1997, 153, 185-192.

22 M. Roerecke and J. Rehm, BMC Med., 2014, 12, 182.

23 J. Rehm, T. K. Greenfield and J. D. Rogers, Am. J. Epidemiol., 2001, 153, 64-71.

24 P. McElduff and A. J. Dobson, Br. Med. J., 1997, 314, 11591164.

25 V. Bagnardi, W. Zatonski, L. Scotti, C. La Vecchia and G. Corrao, J. Epidemiol. Community Health, 2008, 62, 615619.

26 C. J. Holahan, K. K. Schutte, P. L. Brennan, C. K. Holahan and R. H. Moos, Alcohol.: Clin. Exp. Res., 2014, 38, 14321438.

27 J. S. Tolstrup, M. K. Jensen, A. Tjonneland, K. Overvad and M. Gronbaek, Addiction, 2004, 99, 323-330.
28 A. Gea, M. Bes-Rastrollo, E. Toledo, M. Garcia-Lopez, J. J. Beunza, R. Estruch and M. A. Martinez-Gonzalez, Br. J. Nutr., 2014, 111, 1871-1880.

29 M. J. Thun, R. Peto, A. D. Lopez, J. H. Monaco, S. J. Henley, C. W. Heath and R. Doll, N. Engl. J. Med., 1997, 337, 17051714.

30 W. M. Snow, R. Murray, O. Ekuma, S. L. Tyas and G. E. Barnes, Age Ageing, 2009, 38, 206-212.

31 C. Giovanni, R. Luca, B. Vincenzo, Z. Antonella and P. Kari, Addiction, 2000, 95, 1505-1523.

32 L. M. Hines, M. J. Stampfer, J. Ma, J. M. Gaziano, P. M. Ridker, S. E. Hankinson, F. Sacks, E. B. Rimm and D. J. Hunter, N. Engl. J. Med., 2001, 344, 549-555.

33 M. Trevisan, E. Schisterman, A. Mennotti, G. Farchi and S. Conti, Ann. Epidemiol., 2001, 11, 312-319.

34 M. Grønbæk, A. Tjonneland, D. Johansen, C. Stripp and K. Overvad, Eur. J. Clin. Nutr., 2000, 54, 174-176.

35 A. Tjonneland, M. Gronbaek, C. Stripp and K. Overvad, Am. J. Clin. Nutr., 1999, 69, 49-54.

36 F. Ursini, A. Zamburlini, G. Cazzolato, M. Maiorino, G. B. Bon and A. Sevanian, Free Radicals Biol. Med., 1998, 25, 250-252.

37 L. Djoussé, R. C. Ellison, C. E. McLennan, L. A. Cupples, I. Lipinska, G. H. Tofler, N. Gokce and J. A. Vita, Am. J. Cardiol., 1999, 84, 660-664.

38 P. Ventura, A. Bini, R. Panini, L. Marri, A. Tomasi and G. Salvioli, Int. J. Vitam. Nutr. Res., 2004, 74, 137-143.

39 B. Fuhrman, A. Lavy and M. Aviram, Am. J. Clin. Nutr., 1995, 61, 549-554.

40 A. Ceriello, N. Bortolotti, E. Motz, S. Lizzio, B. Catone, R. Assaloni, L. Tonutti and C. Taboga, Eur. J. Clin. Invest., 2001, 31, 322-328.

41 F. Leighton, A. Cuevas, V. Guasch, D. D. Perez, P. Strobel, A. San Martin, U. Urzua, M. S. Diez, R. Foncea, O. Castillo, C. Mizon, M. A. Espinoza, I. Urquiaga, J. Rozowski, A. Maiz and A. Germain, Drugs Exp. Clin. Res., 1999, 25, 133141.

42 D. D. Perez, P. Strobel, R. Foncea, M. S. Diez, L. Vasquez, I. Urquiaga, O. Castillo, A. Cuevas, A. San Martin and F. Leighton, Ann. N. Y. Acad. Sci., 2002, 957, 136-145.

43 A. Di Castelnuovo, S. Costanzo, R. Di Giuseppe, G. de Gaetano and L. Iacoviello, Future Cardiol., 2009, 5, 467-477.

44 C. Heiss, C. L. Keen and M. Kelm, Eur. Heart J., 2010, 31, 2583-2592.

45 S. C. Forester and A. L. Waterhouse, J. Nutr., 2009, 139, 1824S-1831S.

46 M. I. Queipo-Ortuno, M. Boto-Ordonez, M. Murri, J. M. Gomez-Zumaquero, M. Clemente-Postigo, R. Estruch, F. Cardona Diaz, C. Andres-Lacueva and F. J. Tinahones, Am. J. Clin. Nutr., 2012, 95, 1323-1334.

47 S. Maxwell, A. Cruickshank and G. Thorpe, Lancet, 1994, 344, 193-194.

48 T. P. Whitehead, D. Robinson, S. Allaway, J. Syms and A. Hale, Clin. Chem., 1995, 41, 32-35.

49 M. Serafini, G. Maiani and A. Ferro-Luzzi, J. Nutr., 1998, 128, 1003-1007. 
50 M. Serafini, J. A. Laranjinha, L. M. Almeida and G. Maiani, J. Nutr. Biochem., 2000, 11, 585-590.

51 A. Day and D. Stansbie, Clin. Chem., 1995, 41, 1319-1320.

52 S. Maxwell and G. Thorpe, Eur. Heart J., 2000, 21, 14821483.

53 D. Modun, I. Music, J. Vukovic, I. Brizic, V. Katalinic, A. Obad, I. Palada, Z. Dujic and M. Boban, Atherosclerosis, 2008, 197, 250-256.

54 M. I. Covas, P. Gambert, M. Fito and R. De la Torre, Atherosclerosis, 2010, 208, 297-304.

55 C. Stockley, P. L. Teissedre, M. Boban, C. Di Lorenzo and P. Restani, Food Funct., 2012, 3, 995-1007.

56 J. Kanner and T. Lapidot, Free Radical Biol. Med., 2001, 31, 1388-1395.

57 S. Gorelik, M. Ligumsky, R. Kohen and J. Kanner, J. Agric. Food Chem., 2008, 56, 5002-5007.

58 S. Gorelik, M. Ligumsky, R. Kohen and J. Kanner, FASEB J., 2008, 22, 41-46.

59 A. W. Jones, Alcohol.: Clin. Exp. Res., 2000, 24, 400-402.

60 V. A. Ramchandani, P. Y. Kwo and T. K. Li, J. Clin. Pharmacol., 2001, 41, 1345-1350.

61 C. S. Lieber, Drug Metab. Rev., 2004, 36, 511-529.

62 N. Homann, H. Jousimies-Somer, K. Jokelainen, R. Heine and M. Salaspuro, Carcinogenesis, 1997, 18, 1739-1743.

63 E. Marttila, J. Uittamo, P. Rusanen, C. Lindqvist, M. Salaspuro and R. Rautemaa, Oral Surg., Oral Med., Oral Pathol. Oral Radiol., 2013, 116, 61-68.

64 M. Friedman, J. Agric. Food Chem., 2014, 62, 6025-6042.

65 N. Boban, M. Tonkic, D. Budimir, D. Modun, D. Sutlovic, V. Punda-Polic and M. Boban, J. Food Sci., 2010, 75, M322M326.

66 P. Isohanni, T. Alter, P. Saris and U. Lyhs, Poult. Sci., 2010, 89, 2704-2710.

67 A. Nisiotou, N. G. Chorianopoulos, A. Gounadaki, E. Z. Panagou and G. J. Nychas, Int. J. Food Microbiol., 2013, 164, 119-127.

68 A. M. Correia, G. Gonçalves, A. Gomes, B. Oliveira, J. Gonçalves, M. Miranda and O. Almeida, Euro Surveill., 2003, 7, 2195.

69 J. A. Desenclos, K. C. Klontz, M. H. Wilder and R. A. Gunn, Epidemiology, 1992, 3, 371-374.

70 C. Healey, A. Rahman, M. Faizal and P. Kinderman, Int. J. Drug Policy, 2014, 25, 124-132.

71 R. Hingson and A. White, J. Stud. Alcohol Drugs, 2014, 75, 158-169.

72 H. Leifman, Nord. Stud. Alcohol Drugs, 2001, 18, 15-30.
73 B. Hibell, U. Guttormsson, S. Ahlström, O. Balakireva, T. Bjarnason, A. Kokkevi and L. Kraus, The 2007 ESPAD Report - Substance Use Among Students in 35 European Countries, The Swedish Council for Information on Alcohol and Other Drugs (CAN), Stockholm, Sweden, 2009.

74 H. Leifman, E. Österberg and M. Ramstedt, Alcohol in postwar Europe: a discussion of indicators on consumption and alcohol-related harm, European Comparative Alcohol Study - ECAS, 2002.

75 M. Ramstedt, Eur. J. Popul., 2002, 18, 307-323.

76 E. G. Fjaer, W. Pedersen, T. von Soest and P. Gray, Int. J. Drug Policy, 2016, 29, 27-32.

77 D. J. Hanson, Preventing Alcohol Abuse: Alcohol, Culture and Control, Praeger, Westport, 1995.

78 J. H. M. Mendelson and N. K. Mello, Alcohol Use and Abuse in America, Little, Brown, Boston, 1985.

79 N. W. Whitten and M. R. Lipp, To Your Health! Two Physicians Explore the Health Benefits of Wine, Harper Collins, San Francisco, 1994.

80 J. P. David, The consumption of wine and health, OIV, Santiago, Chile, 1994.

81 J. M. Moskowitz, J. Stud. Alcohol, 1989, 50, 54-88.

82 National Social Norms Center at Michigan State University, Target "Low Hanging Fruit" or Highest Risk Groups?, http://socialnorms.org/whole-vs-part-about-audiencesegmentation/.

83 W. H. O. (WHO), Promoting Health Through Schools. Report of a WHO Expert Committee on Comprehensive School Health Education and Promotion WHO, Geneve, Switzerland, 1997.

84 E. Rivella, Groupe d'experts de l'O.I.V., Rapport - A.S. 2349/280296, 1999.

85 W. H. O. (WHO), Youth violence and alcohol fact sheet, Geneva, Switzerland, 2005.

86 M. S. Goodstadt, J. School Health, 1986, 56, 278-281.

87 M. S. Goodstadt, J. Drug Educ., 1986, 16, 349-365.

88 W. Pedersen and T. von Soest, Drug Alcohol Depend., 2013, 133, 587-592.

89 M. C. Chafetz and M. E. Chafetz, Drink Moderately And Live Longer: Understanding The Good Of Alcohol, Scarborough House, 1995.

90 J. B. Davies, The facts about adolescent drug abuse, Cassel, London, 1991.

91 W. Hall, Drug Alcohol Abuse Rev., 2012, 31, 194-197.

92 R. C. Ellison, Ann. N. Y. Acad. Sci., 2002, 957, 1-6.

93 E. Rubin, Alcohol.: Clin. Exp. Res., 2014, 38, 2889-2892. 